\title{
Spatiotemporal Variability of Weather Extremes Over Eastern India: Evidences of Ascertained Long Term Trend Persistence and Effective Global Climate Controls
}

\section{Saurav Saha ( $\nabla$ sauravs.saha@gmail.com )}

ICAR Research Complex for North Eastern Hill Region https://orcid.org/0000-0001-6844-2516

\section{Debasish Chakraborty}

ICAR Research Complex for North Eastern Hill Region

\section{Samarendra Hazarika}

ICAR Research Complex for North Eastern Hill Region

\section{Shakuntala}

ICAR Research Complex for North Eastern Hill Region

\section{Bappa Das}

ICAR Research Complex for North Eastern Hill Region

\section{Aakash Chhabra}

ICAR Research Complex for North Eastern Hill Region

\section{S Sadhu}

ICAR Research Complex for North Eastern Hill Region

\section{Debashis Chakraborty}

ICAR Research Complex for North Eastern Hill Region

\section{J Mukherjee}

ICAR Research Complex for North Eastern Hill Region

\section{Lungmuana Singson}

ICAR Research Complex for North Eastern Hill Region

V.K. Mishra

ICAR Research Complex for North Eastern Hill Region

\section{Research Article}

Keywords: Temperature, Precipitation, Global teleconnection, Agro-eco region, Eastern India

Posted Date: December 6th, 2021

DOI: https://doi.org/10.21203/rs.3.rs-934391/v1 
License: (c) (i) This work is licensed under a Creative Commons Attribution 4.0 International License. Read Full License

Version of Record: A version of this preprint was published at Theoretical and Applied Climatology on February 7th, 2022. See the published version at https://doi.org/10.1007/s00704-022-03949-1. 
MANUSCRIPT TITLE:

2 Spatiotemporal variability of weather extremes over eastern India: Evidences of ascertained long term trend persistence and effective global climate controls

AUTHORS \& AFFILIATION:

A. Saurav Saha*

ICAR Research complex for NEH Region, Mizoram Centre, Kolasib, India

Email: sauravs.saha@gmail.com Phone: +91-8729974473

B. Debasish Chakraborty

ICAR Research complex for NEH Region, Umiam, Meghalaya, India

Email: debasishagri@gmail.com

C. Samarendra Hazarika

ICAR Research complex for NEH Region, Umiam, Meghalaya, India

Email: samarendra.ches@gmail.com

D. I. Shakuntala

ICAR Research complex for NEH Region, Mizoram Centre, Kolasib, India

Email: ishakuntala92@gmail.com

E. Bappa Das

ICAR Central Coastal Agricultural Research Institute, Goa, India

Email: bappa.iari.1989@gmail.com

F. Aakash Chhabra

Department of Civil Engineering, Monash University, Clayton, VIC, Australia

Email: Aakash.Chhabra@monash.edu

G. S. Sadhu

National Statistical Office, Government of India, Kolkata, West Bengal, India

Email: sandip.edu@gmail.com

H. Debashis Chakraborty

Division of Agricultural Physics, Indian Agricultural Research Institute, New Delhi, India Email: debashisiari@gmail.com

I. J. Mukherjee

Division of Agricultural Physics, Indian Agricultural Research Institute, New Delhi, India Email: joydeep.icar@gmail.com

J. Lungmuana Singson

ICAR Research complex for NEH Region, Mizoram Centre, Kolasib, India

Email: 1msingson@gmail.com

K. V.K. Mishra

ICAR Research complex for NEH Region, Umiam, Meghalaya, India

Email: VK.Mishra@icar.gov.in

*CORRESPONDING AUTHOR.

41 Saurav Saha

42 ICAR Research complex for NEH Region, Mizoram Centre, Kolasib, India

43

Email: sauravs.saha@gmail.com Phone: +91-8729974473 


\title{
Spatiotemporal variability of weather extremes over eastern India: Evidences of
} ascertained long term trend persistence and effective global climate controls

\author{
Saurav Saha ${ }^{1}$, Debasish Chakraborty ${ }^{2}$, Samarendra Hazarika ${ }^{2}$, I. Shakuntala ${ }^{1}$, Bappa \\ Das $^{3}$, Aakash Chhabra ${ }^{4}$, S. Sadhu ${ }^{5}$, Debashis Chakraborty ${ }^{6}$, J. Mukherjee ${ }^{6}$, Lungmuana ${ }^{1}$, \\ V.K. Mishra ${ }^{2}$
}

(*Corresponding Author; email: sauravs.saha@gmail.com)

${ }^{1}$ ICAR Research complex for NEH Region, Mizoram Centre, Kolasib, India

${ }^{2}$ ICAR Research complex for NEH Region, Umiam, Meghalaya, India

${ }^{3}$ ICAR Central Coastal Agricultural Research Institute, Goa, India

${ }^{4}$ Department of Civil Engineering, Monash University, Clayton, VIC, Australia

${ }^{5}$ National Statistical Office, Government of India, Kolkata, West Bengal, India

${ }^{6}$ Indian Agricultural Research Institute, New Delhi, India

\begin{abstract}
The present study acknowledged climate variability induced periodic variation in localized extreme weather event occurrences under diverse agro eco-regions of Eastern Himalayas of India during past five decades. The widespread rise in warm nights (TN90p; 0.31-1.67 days year ${ }^{-1}$ ), reduced daily rainfall intensity (SDII) and changes in other weather extremes viz. temperature and precipitation extremes signified clear signals on regional atmospheric warming across eastern India. The agro-ecological regions under extended Bramhaputra valley and coastal belts of south Bengal experienced the most persistent shifts in temperature extremes, while the upper Himalayan range extended from North Bengal to Arunachal Pradesh experienced the steepest decline in average daily rainfall intensity and other absolute quantitative estimates of precipitation extremes over past five decades. Together with El Niño and La Niña events, large scale global atmospheric circulations particularly expansion of warmer Pacific Warm Pool (PWP) and changes in Atlantic Meridional Mode (AMM) contributed the periodic dynamics in weather extreme occurrences from monthly to annual time scale over eastern India. Our findings will be useful for better understanding of regional climatology, designing and successful implantation of location-specific suitable agricultural policies towards climate change adaptation in near future.
\end{abstract}

Keywords: Temperature, Precipitation, Global teleconnection, Agro-eco region, Eastern India. 


\section{Introduction}

Uneven atmospheric warming pattern across the globe evokes the necessity for studying the spatiotemporal variability in climate change phenomenon, which is broadly reported to be more prominent over northern latitudes than mid-latitudes (IPCC, 2013). Anthropogenic climate change-induced significant rise in extreme weather events have been reported across the globe including south and southeast Asian landmass over past few decades (Sen Roy and Balling 2004; Klein Tank et al. 2006; Panda and Kumar 2014; Sharma et al. 2017; Chakraborty et al. 2018; Akhoury and Avishek 2020). Since 1950, the seasonal frequency and magnitude of warm extremes increased with simultaneous decrease in cold extremes over Indian subcontinent (Sharma et al., 2017). The strong effective influence of uneven seasonal surface warming pattern (heatwave; Chakraborty et al. 2018) and other localized phenomenon viz. local terrain features (slope and physiography; Karki et al. 2019), elevation and latitude (Revadekar et al. 2013), urban pollution (Dahutia et al. 2018), land-use changes (Rapp, 2014) and other different meteorological parameters (Revadekar et al. 2013) often modify the seasonal dynamics of regional variation in temperature and precipitation extremes across Indian subcontinent.

The spatial variability in trends of several precipitation extremes increased throughout India during past few decades (Sen Roy and Balling 2004; Revadekar et al. 2013; Chakraborty et al. 2018). After 1980, the relative occurrence of extreme precipitation events increased with variable degrees of spatial aggregation. But minor changes in the mean annual precipitation were recorded from the out-turning impact of anthropogenic atmospheric warming over Indian subcontinent (Nikumbh et al. 2019). The declining trend was evident over two climatologically distinct regions of Central Himalaya (Joshi and Rai 2014; Karki et al. 2019). Such extreme precipitation events were projected to increase in near future and that might have considerable impact on human settlements in south east Asian countries including India (Nikumbh et al. 2019). The dynamic influences of large-scale and sea surface temperature (SST) anomalies had effective control on regional temperature and precipitation extreme events across the Indian Subcontinent (Panda and Kumar 2014). The global teleconnection between periodic SST patterns and seasonal climate extreme dynamics followed the distinct regional patterns over Indo-Pacific (Revadekar et al. 2013), upper Brahmaputra valley (Song et al. 2011), and Myanmar (Sein et al. 2018) region. In India, Sen Roy and Balling (2004) observed no potential linkage for annual precipitation extreme 
events over Indian landmass (1910 - 2000), with either localized regional influences or El Niño South Oscillation events over equatorial Pacific Ocean (Roy et al. 2019). Panda and Kumar (2014) identified the potential control of SST based Niño 3.4 index $\left(5^{\circ} \mathrm{N}-5^{\circ} \mathrm{S}, 120^{\circ}-170^{\circ} \mathrm{W}\right)$ for predicting regional occurrences of forthcoming summer hot days, along with forthcoming heavy precipitation events. The seasonality of wetness pattern in the climate system of North East Indian states is distinct and more prone to meso-scale hydrological disasters from the rest part of India (Saha et al. 2018; Zahan et al. 2021a). To the best of our knowledge, limited information on the regional variability in extreme weather events and the possible linkages with global atmospheric phenomeneon was available from the humid to per-humid and tropical to sub temperate climate of eastern Himalayan region of Indiaand its adjacent river basins having variable agro-ecology (Abul Basher et al. 2017). Therefore, detailed investigations were worthwhile with the following objectives (a) to assess the regional variability in temperature and precipitation extreme events across delineated agro-eco regions (AERs) in eastern India over past five decades, (b) to investigate the interconnection between regional weather extreme event occurrences and global teleconnection indices.

\section{Methodology}

Data availability, quality control and calculation of extreme indices: The daily temperature (maximum and minimum) and precipitation data of 36 surface weather stations were obtained from the India Meteorological Department (IMD-Government of India; 1969-2018). The surface weather stations were spread over $\sim 3,28,238 \mathrm{~km}^{2}$ area between $21^{\circ} 46^{\prime}-28^{\circ} 06^{\prime} \mathrm{N}$ latitudes and $86^{\circ} 22^{\prime}-94^{\circ} 55^{\prime} \mathrm{E}$ longitudes having variable relief features between 1 to $2042 \mathrm{~m}$ above mean sea level a. m. s. 1. (Fig. 1). The study region selected here encompasses six distinct AERs as delineated by ICAR- National Bureau of Soil Survey and Land Use Planning (NBSS\&LUP) (Mandal et al. 2016), covering spatially diverse landscape features viz. temperate to sub temperate regions of Sikkim Himalaya, Meghalaya plateau (Khasi, Garo and Jaintia range), tropical to subtropical belt of Naga and Chin hills, Bramhaputra and Barak valley of Assam and lower Gangetic plains of West Bengal.

We adapted the open-source freely available package R programming based "RClimDex" software package, developed by Expert Team on Climate Change Detection, Monitoring and Indices (ETCCDMI; http://etccdi.pacificclimate.org/indices.shtml.; table 1) and recommended for 
data quality control for weather extreme analysis (Zhang et al. 2018). For minimizing error in trend analysis, we checked the station wise weather data quality for homogeneity, identification of missing values and potentially unrealistic/doubtful records. Missing data gaps were filled with IMD gridded data sets, after comparing with corresponding nearest grid point values. The higher deviations in derived weather parameters in five stations likely, Cherrapunjee, Shillong, Gangtok, Darjeeling and Kalimpong restricted the adaptation of IMD gridded data for gap filling (Supplementary Fig 1a-d). Therefore, we accounted for the long term daily average values as an alternative approach for filling the missing values of daily surface observations for these five hill stations. However, the total number of observation replacements (temperature and precipitation) was less than $8 \%$ of the total number of recorded ground data points. Lastly, the data inhomogeneity was checked in the R-based "RClimDex-Extraqc" and "RH tests version4 (RHtestsV4)" software packages (Wang and Feng 2013). We detected some station wise shifts in data series from the homogenization analysis (Supplementary table 1). The detected sifts were adjusted simultaneously using the bootstrapping approach in the same software package without homogenous reference series for avoiding artificial jumps at the initiation or terminal point of the time series. Thereafter, we warranted no further data adjustment and calculated the ETCCDMI recommended extreme weather indices with $\leq 1$ year return period. The base period of 1981-2010 was fixed and it accounted for more than $85 \%$ of stations with valid values for making representative counts of days, crossing climatological percentile thresholds for extreme weather indices calculation. All the extreme weather event analyses were carried out from annual to seasonal timescale boundaries as delineated by IMD for India viz. winter (January-February), premonsoon (March-May), monsoon (June -September) and post-monsoon (October-December). Finally, regional averaged anomaly series for assessing AER wise extreme indices were aggregated as:

$$
x_{r, t}=\sum_{i=1}^{n}\left(x_{i, t}-\bar{x}_{\imath}\right) / n
$$

Where, $x_{r, t}$ is averaged extreme index value at $\mathrm{t}^{\text {th }}$ year for any particular AER; $x_{i, t}$ is index for station $\mathrm{i}$ for $\mathrm{t}^{\text {th }}$ year; $\overline{x_{l}}$ is the mean index for any particular station I (1969-2018); $\mathrm{n}$ is total number of stations with available data for year $t$ within the delineated AER.

Trend analysis: Seasonal extreme indices time series rarely follow normal distribution. Hence, we adapted non-parametric Mann-Kendall test (MKT) instead of simple linear least squares trend, as 
recommended by the WMO for trend assessment and statistical significance (Saha et al. 2018). We accounted autocorrelation function $(\mathrm{ACF})$ for eliminating the serial correlation effect, prior to final trend assessment in station wise temperature/ precipitation extreme event time series and estimated the slope magnitude or changes per unit time irrespective of gross data errors or outliers. The majority of the time series were free from serial correlation at lag-1. We adapted three-stage pre-whitening method before performing the final trend estimation if first order autocorrelation was significant at $\mathrm{p}<0.05$ (data not presented; Zhang et al. 2018).

Hurst exponent analysis: We adapted the widely used robust statistical method of estimating Hurst exponent for detecting the persistence of long-term processes that occur in the extreme event time series (Hurst 1951); via classical rescaled range analysis for the time series $\{\xi(t)\}(t=1,2, \ldots, n)$ and dividing it into $\tau$ sub-series $x(\mathrm{t})$,

Arithmetic mean sequence $\left(\xi_{\tau}\right)=\sum_{t=1}^{\tau} \mathrm{x}(\tau) / \tau \tau=1,2, \ldots . \mathrm{n}$

Cumulative deviation: $\mathrm{X}(\mathrm{t}, \tau)=\sum_{t=1}^{\tau}(\xi(\mathrm{u})-(\xi) \tau) \quad 1 \leq \mathrm{t} \leq \tau$

Range sequence: $\mathrm{R}(\tau)=\max _{1 \leq t \leq \tau} \mathrm{X}(\mathrm{t}, \tau)-\min _{1 \leq t \leq \tau} \mathrm{X}(\mathrm{t}, \tau)$ where, $\tau=1,2, \ldots . \mathrm{n}$

Sequence of standard deviation: $S(\tau)=\left[\frac{1}{\tau} \sum_{t=1}^{\tau}(\xi(\mathrm{u})-(\xi) \tau)^{2}\right]^{\frac{1}{2}} \quad \tau=1,2, \ldots . \mathrm{n}$

Therefore, Hurst exponent $(\mathrm{H})$ was expressed as:

$$
\frac{R(\tau)}{S(\tau)}=(\mathrm{c} \tau)^{\mathrm{H}}
$$

Generally, $\mathrm{H}$ varied between 0 and 1 . Higher $\mathrm{H}$ values $(0.5<\mathrm{H}<1)$ indicated trend sustainability; $\mathrm{H}=0.5$ signified a random walk and lower $\mathrm{H}$ values signified trend antisustainability $(0<\mathrm{H}<0.5)$ in long run.

Linking regional weather extreme events with global climate anomalies: The climatic system of Indian subcontinent indicated relationship with several large-scale global atmospheric circulation/ teleconnection indices (Supplementary table 2), along with rising levels of atmospheric greenhouse gas (GHG) concentration viz. $\mathrm{CO}_{2}$ and $\mathrm{CH}_{4}$ and solar activity. In this study, we analyzed their internal co-variation and association with de-trended (linear) extreme event time series. Initially, we adapted Principal Component Analysis (PCA) for minimizing the dimensionality of available global teleconnection time series, while retaining the largest variance 
present in the analyzed dataset through identified dominant principal components (PCs). The initial pre-filtering technique ensured that first PC explained maximum variability followed by others in descending manner. We identified and retained the important underlying variables for each PC based on absolute factor loadings values within $10 \%$ of the maximum weighted factor. Furthermore, we cross verified the inter-linkage of extracted variables for all the respective PCs using Pearson Correlation matrix and finally selected the most non co-related variables from each PC for further co-variation analysis. The maximum likelihood for linear associations between two respective orthogonal datasets viz. time series of all the global climate anomaly datasets and periodic regional weather extreme event occurrences was quantified on the calculation of canonical coefficients (de-trended time series) using singular value decomposition of crosscovariance matrix over monthly and annual time scale.

Testing for co-integration: We adapted Johansen's methodology for assessing the final degree of association between the sets of time series viz. composite weather extreme time series and global climate controls (Johansen and Juselius 1990). The starting point of p order in vector autoregression was,

$\mathrm{y}_{\mathrm{t}}=\mu+\mathrm{A}_{1} \mathrm{y}_{\mathrm{t}-1}+\ldots .+\mathrm{A}_{\mathrm{p}} \mathrm{y}_{\mathrm{t}-\mathrm{p}}+\varepsilon_{\mathrm{t}}$

Where $y_{t}$ is $n x 1$ vector of variables; integrated of order one expressed as $I ; \varepsilon_{t}$ implies vector of innovations for $n x 1$. Therefore, vector autoregression was expressed as

$\Delta \mathrm{y}_{\mathrm{t}}=\mu+\prod \mathrm{y}_{\mathrm{y}-1}+\sum_{i=1}^{p-1} \Gamma_{i} \Delta y_{t-i}+\varepsilon_{t}$

Where,

$\Pi=\sum_{i-1}^{p} \mathrm{~A}_{i}-\mathrm{I}$ and $\Gamma_{i}=-\sum_{j=i-1}^{p} A_{j}$

If $r<n$ for the coefficient matrix (П), then $n x r$ matrices $\alpha$ and $\beta$ each with rank $\mathrm{r}$ expressed the stationarity as $\Pi=\alpha \beta^{\prime}$ and $\beta^{\prime} y_{t}$ for the $r$ number of co-integrating relationships. Here, $\alpha$ denoted the adjustment parameters in vector error correction model and each column of $\beta$ implied the co-integrating vector. For any specific $r$ value, the maximum likelihood estimator for $\beta$ defined the combination of $\mathrm{y}_{\mathrm{t}-1}$ that yielded the $\mathrm{r}$ largest canonical correlations of $\Delta \mathrm{y}_{\mathrm{t}}$ with $\mathrm{y}_{\mathrm{t}-1}$ with corrected lag differences and deterministic variables (if any). Furthermore, two different likelihood 
217 ratio tests of significance for these canonical correlations viz. trace test and maximum eigenvalue

218 test were executed with reduced rank of $\prod$ matrix, respectively as.

$219 \quad \mathrm{~J}_{\text {trace }}=-\mathrm{T} \sum_{i=r-1}^{n} 1 n\left(1-\hat{\lambda}_{i}\right)$

$220 J_{\max }=-\mathrm{T} \ln \left(1-\hat{\lambda}_{r+1}\right)$

221

Where, $\hat{\lambda}_{i}$ is $\mathrm{i}^{\text {th }}$ largest canonical correlation for the sample size of $\mathrm{T}$. The trace test tested

$222 \mathrm{H}_{\mathrm{o}}$ for $\mathrm{r}$ numbers of co-integrating vectors against the alternative hypothesis $\left(\mathrm{H}_{1}\right)$ of $\mathrm{n}$ co-

223 integrating vectors. In courtesy, the maximum eigenvalue test considered $\mathrm{H}_{0}$ of $\mathrm{r}$ co-integrating

224 vectors against the alternative hypothesis $\left(\mathrm{H}_{1}\right)$ for $\mathrm{r}+1$ co-integrating vectors. Neither of these two

225 test statistics followed chi-square distribution. We used asymptotic critical value approach for 226 assessing co-integration for each AER separately using maximum eigenvalue for $\mathrm{r}=0$ or 1

227 (Johansen and Juselius, 1990). At $\mathrm{p}<0.05$, the critical values for $\mathrm{r}=0$ is $8.18(11.65 ; \mathrm{p}<0.01)$ while

228 that of $\mathrm{r}=1$ is $14.9(19.19 ; \mathrm{p}<0.01)$. For all those series where either of the null hypothesis has

229 been accepted, implying a reduced rank of $\prod$, have a common long term trend. Where both the

230 null hypothesis is rejected, the test statistic values were omitted signifying no long-term

231 relationship between two sets of time series.

232 3. Results

Rainfall climatology of the study region varied from perhumid to sub-humid type with core 234 south west monsoon activity (Mandal et al. 2016). According to Koppen climate classification, 235 tropical climate (category A) exist across the parts of Manipur, Mizoram, Tripura and Cachar plain 236 of Assam (below $25^{\circ} \mathrm{N}$ latitude). The remaining region of Meghalaya, Assam (upper Bramhaputra 237 valley), Manipur, Nagaland and parts of Arunachal Pradesh (within $25^{\circ}$ and $35^{\circ} \mathrm{N}$ latitude) fall 238 under warm temperate mesothermal climate. The mean monthly maximum temperature varied 239 between $24.5^{\circ} \mathrm{C}$ (AER 17) to $35.2^{\circ} \mathrm{C}$ (AER 12) across the region (summer months; during June240 July). In courtesy, the average minimum monthly temperature was assorted between $6.1{ }^{\circ} \mathrm{C}$ (AER 241 17) to $13.9{ }^{\circ} \mathrm{C}$ (AER 12) during winter months (December-January). South west monsoon 242 contributed the major share (66.1-78.4\%) of annual precipitation varying between $1532.2 \mathrm{~mm}$ 243 (AER 12) to $3782.32 \mathrm{~mm}$ (AER 18) over eastern India (Saha et al. 2018).

\section{$244 \quad 3.1$ Trend pattern and persistence analysis of extreme weather events:}


3.1.1 Seasonal and annual temperature extreme pattern: Substantial spatiotemporal variability in long term seasonal changes of weather extreme events were conspicuous across the six AERs of eastern India over the past five decades (Sharma et al. 2017). The results of trend pattern and its persistence of the daily temperature extreme accumulated over different seasons are presented in figure $2 \mathrm{a}$ and $\mathrm{b}$. Seasonal changes in warm nights (TN90p) were more extensive and occurring over different seasons than observed changes in warm days (TX90p), cool nights (TN10p) and cool days (TX10). The hottest maximum temperature (TXx; warmest day) showed maximum trend/change followed by warmest minimum temperature (TNx; warmest night), coldest minimum temperature (TNn; coldest night) and coldest maximum temperature (TXn; coldest day) across AERs in eastern India (Fig 2a). The prudent spatiotemporal variability in Sen slope values was more conspicuous from seasonal to annual time scale. The significant rise in TXx over AER 19 (0.03-0.05 ${ }^{\circ} \mathrm{C}$ year $\left.{ }^{-1}\right)$ was accompanied by increased TNx over AER 18 and AER 19 (0.01-0.07 ${ }^{\circ} \mathrm{C}$ year $\left.^{-1}\right)$ over all the four seasons. In similarity, the overall seasonal TXn rise over AER 17 (0.02$\left.0.06{ }^{\circ} \mathrm{C}_{\text {year }}{ }^{-1}\right)$ and AER $18\left(0.01-0.04{ }^{\circ} \mathrm{C}_{\text {year }}{ }^{-1}\right)$ were more divergent with the observed decline in TXn over AER 15, particularly during winter and post-monsoon season $\left(0.06-0.14{ }^{\circ} \mathrm{C}\right.$ year $\left.{ }^{-1}\right)$. The declined winter TNn over AER 12 and AER $19\left(\sim 0.04{ }^{\circ} \mathrm{C}\right.$ year $\left.{ }^{-1}\right)$ were also contrasted with TNn rise across AER 18, AER 17 and AER 12 during pre-monsoon season (0.03-0.06 $\left.{ }^{\circ} \mathrm{C}_{\text {year }}{ }^{-1}\right)$. However, the declining trend of TNn over AER 19 was anti-persistent during monsoon months (Fig 2b). The relative changes in minimum temperature based extreme indices (TN10p, TN90p, TNn and TNx) were more widespread, intense and ubiquitous than maximum temperature-based indices (TX10p, TX90p, TXn and TNx). Spatially, mixed trend patterns existed for both minimum and maximum temperature based extreme indices among the delineated AERs from seasonal to annual time scale. The strongest widespread changes in minimum temperature-based percentile index (TN90p; 0.31-1.67 days year ${ }^{-1}$ ) indicated more explicit lengthening of warm nights over eastern India during all four seasons. Throughout AER 18, significant lengthening of warm days (TX90p; $0.41-0.76$ days year ${ }^{-1}$ ) and summer days (SU25; 1.09 days year ${ }^{-1}$ ) with increased warm

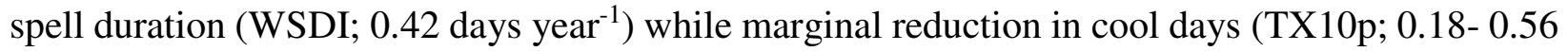
days year ${ }^{-1}$ ) were apparently confirming incessant seasonal warming across eastern India. In contrary, substantial rise in warm nights (TN90p; 0.62 -1.09 days year ${ }^{-1}$ ) ascribed the observed protraction of tropical nights (TR20; 0.85 days year ${ }^{-1}$ ) over AER 18. Reduction in warm days (TX90p; 0.31-62 days year ${ }^{-1}$ ) during different seasons imparted the overall annual reduction in 
summer days (SU25; 0.73 days year ${ }^{-1}$ ) over AER 17 with no significant changes in warm night (TN90p) and tropical night (TR20). The consistent high magnitude of year-round TN90p rise (0.78-1.51 days year $\left.{ }^{-1}\right)$ ensured the annual occurrences of prolonged tropical night over AER 18 and AER 16 (TR20; 0.32- 0.85 days year $^{-1}$ ). Consistent reduction in seasonal cool nights (TN10p; 0.41-0.53 days year ${ }^{-1}$ ), rise in frequent warm days (TX90p; $0.26-1.08$ days year ${ }^{-1}$ ) and lengthy warm spells (WSDI; $\sim 0.41$ days year $^{-1}$ ) contributed to further lengthening of tropical nights (TR20) over AER 16. The relative reduction of cool nights was in consonance with the observed reduction in summer days (SU25; 1.64 days year ${ }^{-1}$ ) over AER 12. The consistent seasonal rise in cool days (TX10p; 0.6-1.4 days year ${ }^{-1}$ ) complemented strong annual decline in summer days (SU25; 0.32 1.31 days year $^{-1}$ ) over AER 15 and AER 19. The increased occurrences of cool nights (TN10p) during post-monsoon and winter (0.8-1.5 days year $\left.{ }^{-1}\right)$ acceded the rise in cold spell duration (CSDI; 0.37 days year $^{-1}$ ) over AER 19.

The significant seasonal constriction in DTR was evident in AER $15\left(0.027-0.053^{\circ} \mathrm{C}_{\text {year }}^{-}\right.$ $\left.{ }^{1}\right)$ against the distinct rise in seasonal DTR across AER $18\left(0.039-0.009{ }^{\circ} \mathrm{C}\right.$ year $\left.{ }^{-1}\right)$ for all four seasons. The DTR fluctuations were more rapid during winter than monsoon season. The declined monsoon and post-monsoon DTR ranged across AER 17, AER 15 and AER $12\left(0.01-0.04{ }^{\circ} \mathrm{C}\right.$ year $\left.^{-1}\right)$. The fluctuations in seasonal temperature extremes were more prominent during winter and pre-monsoon over AER $19\left(\sim 0.02{ }^{\circ} \mathrm{C}_{\text {year }}{ }^{-1}\right)$. With few exceptions, the significant decline in DTR time series was persistent with higher trend sustainability across all the six AERs in eastern India (Song et al. 2011). Eventually, AER 18 and AER 19 were exposed to increased daily fluctuations in maximum and minimum temperature, while AER 17 experienced the least overall seasonal fluctuations in temperature extremes.

\subsubsection{Seasonal and annual precipitation extreme pattern:}

The spatial variability in precipitation extreme trend was more splintered with limited spatial coherence than observed trend pattern in extreme temperature time series over eastern India (Klein Tank et al. 2006; Nikumbh et al. 2019). The results of this study indicated significant decline in majority of extreme precipitation indices, like number of precipitation days, absolute precipitation quantity and intensity except CDD $\left(0.24-3.11\right.$ days year $\left.^{-1}\right)$ and CWD (0.27-0.35 days year ${ }^{-1}$ ). The declining trend in RX1 was almost identical with RX5, particularly during monsoon months across the majority of AERs in eastern India. 
The significant increase of annual CDD $\left(0.54\right.$ days year $\left.^{-1}\right)$ and ZRD $(0.05-0.18$ days year

$30{ }^{1}$ ), along with marginal reduction in CWD (0.35 days year $\left.{ }^{-1}\right)$ and number of heavy precipitation

308

309

310

311

312

313

314

315

316

317

318

319

320

321

322

323

324

325

326

327

328

329 days $\left(0.25\right.$ days year $\left.{ }^{-1}\right)$ revealed the rising annual dryness over AER 18 . The increasing anomalies in seasonal and annual precipitation extreme time series were evident from the sharp decline in absolute precipitation quantity indices (5.11 -29.03 mm PRCPTOT year ${ }^{-1}$; 3.18 -11.25 mm R95p year $^{-1}$; 1.76- 4.44 mm R99p year ${ }^{-1}$; 0.03-1.3 mm RX1 year ${ }^{-1}$ ), intensity indices (SDII; 0.05-0.11 $\mathrm{mm} \mathrm{day}^{-1}$ year $\left.^{-1}\right)$ and number of precipitation days (0.69-2.11 days CDD year ${ }^{-1} ; 0.15-0.23$ days CWD year-1; 0.03-0.11 days ZRD year ${ }^{-1}$; 0.07-0.6 days R10 year ${ }^{-1}$ and 0.15-0.53 days R20 year ${ }^{-1}$ ) over AER 17, AER 16 and AER 15. Our result was in contrast with the increasing trend of heavy rainfall events across north east India (Guhathakurta et al. 2011). However, more intense shifts in seasonal and annual precipitation extreme events towards the respective increases in regional dryness were evident across AER 17 and AER 16. While the reduced average daily rainfall intensity (SDII; $0.07 \mathrm{~mm} \mathrm{day}^{-1}$ year $^{-1}$ ) and very wet days occurrences (R95p; $4.47 \mathrm{~mm} \mathrm{year}^{-1}$ ) progressed towards more uneven annual precipitation distribution through observed rise in CWD (0.27 days year $\left.{ }^{-1}\right)$ over AER 12 . In contrast, raising average daily rainfall intensity $\left(0.05 \mathrm{~mm} \mathrm{day}^{-}\right.$

${ }^{1}$ year $^{-1}$ ) and very wet day occurrences (R95p; $4.71 \mathrm{~mm}$ year $^{-1}$ ) were accompanied by frequent dry spell events (CDD; 0.48 days year ${ }^{-1}$ ) over AER 19. Majority of the observed trend pattern and significant changes in periodic weather extremes were persistent over the delineated AERs in eastern India. In contrast, the observed annual decline in RX5, R95p, and R99p over AER 15 along with changes in R50 over AER 17 were anti-persistent (Fig. 2b). The sustainability of significant gradual shifts identified in annual precipitation extremes time series towards dryness was conserved (Panda and Kumar, 2014).

\subsection{Association with large-scale global atmospheric circulation}

We assessed the relationship between extreme weather indices and large-scale global atmospheric circulation for the period 1969-2018.

\subsubsection{Principal component analysis:}

Multiple indices of large-scale global atmospheric circulation processes have indirect control on weather extremes over the study region. Principal Component Analysis (PCA) were adapted for minimizing the dimensionality of global teleconnection time series, while retaining the largest variance in dataset. The eigenvalues of nine principal components (PCs) were $\geq 1$ that accounted 
$89.58 \%$ cumulative variance in the data set (Table 2). Strong correlation among the dominated global teleconnection indices with each PC was cross verified. Indices having weightage within $10 \%$ of the highest factor loading for each eigenvalue represented the variability of respective PCs. Therefore, we sorted out nine indices viz. Oceanic Niño Index (ONI; PC 1), Pacific Warm Pool (PWP; PC 2), North Atlantic Oscillation (NAO; PC 3), North Pacific pattern (NP; PC 4), East Pacific/North Pacific Oscillation (EPNP; PC 5), Western Pacific Index (WP; PC 6), Atlantic Meridional Mode (AMM; PC 7), Trans-Niño Index (TNI; PC 8) and Quasi-Biennial Oscillation (QBO; PC 9) for further association analysis with temperature and precipitation extreme time series in eastern India.

\subsubsection{Canonical correlation analysis:}

Canonical correlations between respective global teleconnection and extreme weather time series were carried out from monthly to annual time scales, particularly for El Niño and La Niña years (Table 3). Multivariate Wilks' lambda $(\lambda)$ test identified significant strong association $(\mathrm{p}<0.01)$ between global teleconnection and monthly weather extreme time series accounting $82.84 \%$ and $87.92 \%$ cumulative variability during the El Niño $(\lambda: 0.058-0.562)$ and La Niña $(\lambda: 0.067-0.605)$ years, respectively. The corresponding eigenvalues represented the changes in strength of association with declining degree of canonical correlations through accommodating more cumulative variability at $\mathrm{p}<0.05$ significance level. The multifactor linkage between global teleconnection and weather extreme series was stronger for monthly $(\lambda: 0.182-0.904$, variability: $95.10 \%)$ rather than annual time scale $(\lambda: 0.001$, variability: $21.41 \%)$. The respective multivariate helio-plots displayed the extent of linkage using radial bars (Fig. 3a-d). Smaller weightage points were put inward, and larger values pointed outwards from the base. The directions of placement laid down the nature of linkages i.e. direct or inverse relationship. PWP had the most effective influence on weather extreme event occurrences over eastern India, followed by North Pacific pattern (NP). The influence of PWP were more implicit for rising warm nights (TN90p) than warm days (TX90p) occurrences from monthly to annual time scale over our present study region (including El Niño and La Niña years). Furthermore, the proportionate direct influence of NP over both absolute temperature (TXx, TNx, TXn and TNn) and precipitation (RX1 and RX5) extremes also affirmed the role of pacific warming in Eastern India. The moderate control from Oceanic Niño Index (ONI; El Niño years) and Atlantic Meridional Mode (AMM; La Niña years) influenced 
the dynamics of cool day occurrences (Fig 3a and b; Panda and Kumar, 2014). Nevertheless, ONI facilitated the proportionate rise in periodic occurrences of absolute extreme temperature and precipitation indices and suppressed the rise in ZRD and DTR fluctuations during La Niña years (Fig. 3b). The combined influence from AMM and WP was also inevitable during La Niña years. On monthly time scale, warm night occurrences were closely associated with variations in PWP. The prominent control of NP on overall monthly variations in absolute temperature and precipitation indices were evident during our present study period (Fig. 3c). In contrary, AMM commenced the prominent control on annual distribution of consecutive wet day (CWD) and tropical night (TR20) occurrences (Fig. 3d). East Pacific/North Pacific Oscillation swayed the annual occurrences of absolute precipitation quantity (PRCPTOT, R95p and R99p) and average rainfall intensity (SDII) across the AERs. Unlike Song et al (2014), we observed very limited forcing of NAO and QBO on regional weather extreme occurrences from monthly to annual time scale over Eastern India.

\subsubsection{Cointegration analysis:}

The weather extremes over eastern India and global teleconnections varied over time implying their non-stationarity, while the lag-1 differenced series of the indices showed stable mean over time. Most of the weather extreme indices showed co-movement with the selective/specific global teleconnection indices over time and depicted a common long-term trend for co-integration between the two sets of time series at monthly and seasonal time scale (table $4 \mathrm{a}$ and b). The relative control of PWP (except CDD and CWD) and AMM on weather extreme event occurrences of eastern India were very clear from monthly to annual time scale. Nevertheless, the ascendency of ONI was limited for monthly variation in weather extreme event occurrences, particularly during El Niño or La Niña years (Fig 3a and b; Table 4b). The relative control of ONI on annual occurrences of TN90p and TR20 were significant. Even so, the ascendancy of EPNP was evident for periodic precipitation extreme occurrences across eastern India. The rise in anthropogenic GHG (mostly $\mathrm{CH}_{4}$ and $\mathrm{CO}_{2}$ ) showed strong co-integration with the changes in weather extreme event time series (Table 5). The influence of changing emission rate of $\mathrm{CH}_{4}$ was most common for all studied weather extreme indices of the study region. The rise in atmospheric $\mathrm{CO}_{2}$ concentration was not associated with the dynamics of daily precipitation intensity and wet days occurrences over the study region. The annual variations in OLR were closely associated with 
the observed variation in absolute precipitation quantity (PRCPTOT, R95p and R99p), but have limited influence on intensity or number of precipitation days (except ZRD counts). The natural variations in sunspot activity and solar flux were analogous to the annual DTR fluctuation and TN90p occurrences.

\section{Discussion:}

In the present study, we assessed the trend and its persistence of daily temperature and precipitation extreme indices calculated from the quality-controlled and homogenized dataset for 36 surface weather stations across eastern India for the period of 1969-2018 (Fig. 2a and b). The widespread rise in warm night occurrences came up with the evidence of clear rise in nocturnal temperature extreme events over daytime ones across the eastern India (Choi et al. 2009; Sein et al. 2018). The strong warming trend was mostly recorded during monsoon months (June-JulyAugust-September) especially for warm nights (Song et al. 2011). The agro-eco regions categorized under Purvanchal range (AER 18), Assam - North Bengal plains (AER 16) and coastal belt of south Bengal (AER 19) were pre-disposed with significant rise in warmer day temperature extremes (warm days; TX90p) and subsequent decline in cool night (TN10p) occurrences, particularly over AER 18 (Chakraborty et al. 2018). The contrasting rising trend in cold day temperature extremes (TX10p) were more conspicuous over Bengal basin (AER 15) and costal belts of south Bengal region (AER 19) than other adjacent AERs (Sharma et al. 2017). The rise in TXx and TNn showed higher spatial coherence than TNx and TXn across the delineated AERs in eastern India (Revadekar et al. 2013). Unlike other parts of India, the changing magnitudes in minimum temperature trends and its variability were almost equally evident for the maximum temperature extremes throughout the year (Sein et al. 2018). The greater magnitude of rising minimum temperature over maximum temperature resulted the observed reduction in DTR over eastern India except, the Purvanchal range (AER 18) and coastal regions of south Bengal (AER 19) (Klein Tank et al., 2006). Fragmented decrease in cloud cover and increase in afternoon RH across AER 18 steered the localized DTR rise as also reported from adjacent Myanmar region (Sein et al. 2018). In contrast, the climate control of increased cloud cover (Jaswal 2010) and reduced insolation (Jhajharia and Singh 2011) over rest AERs and other non-climatic factors like rapid urbanization and increasing aerosols levels and water-vapor feedbacks contributed to the observed anomalies for reduced DTR in eastern India (Song et al. 2011; Dahutia et al. 2018). 
The high mountainous topography of Eastern Himalaya region (including Sikkim Himalaya; AER 17) and adjacent plains in upper Bramhaputra plains (Assam and North Bengal; AER 16) were more prone to strong changes in dry precipitation extreme events than other AERs like Purvanchal range (AER 18), plains of Gangetic Bengal viz. AER 15, AER 12 and AER 19 in eastern India over past five decades (Panda and Kumar, 2014). In contrast with reported increase in wet extreme precipitation events in Upper Brahmaputra Valley of China (Song et al. 2011), robust pattern of changes in seasonal frequency and intensity of dry and wet spell occurrences were reported from the fragmented landlocked regions of extended eastern Himalayan region in neighboring Bangladesh (Abul Basher et al. 2017). Our findings were in synchrony with the increased dry precipitation events during post-monsoon months at Umiam (Choudhury et al. 2012) and pre-monsoon/ monsoon moths in northeast Bangladesh (Abul Basher et al. 2017). Several global climate models projected decline in precipitation with increased precipitation extremes during the warmer $21^{\text {st }}$ century with rising ZRD (Panda and Kumar 2014). The decreased monsoon depression days and rising magnitude of low-pressure systems contributed to the observed spatial variability in declining trends in heavy rainfall extremes with increased frequency of dry spell events over North East India (Panda and Kumar 2014). The widespread significant decline in SDII across AER 12, AER 15, AER 16 and AER 17 contradicted the projected more intense precipitation from the reported rise in atmospheric temperature and supportive increase in moisture-holding capacity of the air across eastern India (Trenberth, 2011). Despite rise in air temperature, increased aerosol loading and cloud optical depth may contribute to the observed decreasing trends of rainfall intensity with increased dry precipitation extremes events over eastern India (Dahutia et al. 2018). Nevertheless, localized land use/land cover changes like massive deforestation, expansion of cultivable land and wasteland area ensued decrease (increase) in latent (sensible) heat flux, stimulating ground heat buildup and surface energy imbalance (Rapp 2014). Such alterations lead to lower evapotranspiration rate and reduced convection emanated drier precipitation extreme occurrences across eastern India region (Kumar 2021). In contrary, the combined rise in extreme temperature and precipitation events (dry spells; Panda and Kumar 2014) raised the potential risk of alteration in plant crop bio-physical processes and productivity from seasonal weather aberrations, across the upper Bramhaputra Basin in Assam and Gangetic plains of Bengal. 
Several previous studies on temperature and precipitation extremes around the world have confirmed the potential linkages between extreme temperature or drier precipitation events and periodic variability/pattern in large-scale global atmospheric circulation as well as Global teleconnection (Akhoury and Avishek 2020). Differential atmospheric warming over land and sea surface eventually enabled the changes in atmospheric waves generated by thermal kinematic perturbations that tethered the periodic perturbations to regional variations in weather extreme event occurrences over the Eastern India region (Prokop and Walanus 2014). Co-integration analysis confirmed the modulation of El Niño teleconnection with monthly weather extreme occurrences over eastern India (Sein et al. 2018). The strapping regional regulations of El Niño events (positive association; Ihara et al. 2006) on warmer temperature extreme occurrences were more evident over eastern India (Song et al. 2011; Sein et al. 2018); but such controls were truant during prominent La Niña years (Table 3a and b; Ihara et al. 2006). However, the degree of dependence of non-stationary El Niño teleconnection gradually thinned down while approaching from monthly to annual time scale (Fig 3a-d; Goddard and Gershunov 2021). Moreover, PWP $\left(60^{\circ} \mathrm{E}-170^{\circ} \mathrm{E}\right.$ to $15^{\circ} \mathrm{S}-15^{\circ} \mathrm{N}$ with $\mathrm{SST}>28^{\circ} \mathrm{C}$ isotherm) played the central role in determining the relative frequency and spatial extent of extreme event occurrences over the past five decades across different agro-eco regions of Eastern India (Table 4a; Zahan et al. 2021b). This enhanced anthropogenic heat sequestration within western equatorial Pacific waters facilitated the east west movement of PWP and strongly impacted the periodic variation in El Niño-Southern Oscillation (ENSO event expressed in terms of ONI) events during past few decades (Dang et al. 2020). The strong remote forcing of periodic PWP oscillation was closely linked with ENSO phenomenon in equatorial Pacific zone (Misra et al. 2016). Expanded (contracted) PWP and atmospheric convective zone development was inter-coupled with El Niño (La Niña) phase of ENSO phenomenon (Roy et al. 2019). In similarity, the ONI time series further strengthened the linkage with monthly regional weather extreme event anomalies over eastern India, particularly during El Niño and La Niña years (Fig 3a, b and c). El Niño and La Niña events were generally opposite for determining the periodic variations in weather extremes. The cumulative forcing of monthly global teleconnection time series dominated over annual time scale (Table 4a and b; Prasad and Singh 1996). The anthropogenic GHG emission induced global warming accelerated the rapid area expansion for warmer Tropical Ocean under PWP subdued the natural decadal oscillation from changing solar flux and sunspot activity in order to determine extent of observed regional weather 
extreme anomalies over eastern India (Table $4 \mathrm{~b}$ and table 5). The net impact was accounted from increased dry spells, reduced absolute precipitation quantity and rainfall intensity under modified core monsoonal activity over the eastern Himalaya region (Weller et al. 2016). In addition, the contrasting phases of $\mathrm{AMM}$ over $0^{\circ}-80^{\circ} \mathrm{N}$ posed the additional influence through modified wind circulation pattern on extreme weather events over eastern India (Joshi and Rai 2014).

\section{Conclusion:}

Climate change induced modifications accounted for the recorded changes in seasonal dynamics of extreme weather events (both frequencies and magnitude) aggregated across the delineated AERs in eastern India over past five decades. Our results were in consilience with Global teleconnections; rising warmer temperatures and drier precipitation extremes are highly likely to have profound adverse impact on regional water resource availability, alteration of agricultural productivity, ecosystem functioning and human health in eastern India. Rising green house gas concentration effectively contributed the observed extreme event anomalies rather than natural climatic controls lik solar activity over estern India region. Regional location-specific policy formulation needs to increase preparedness to keep down the disaster risk and supportive coping strategy formulation for are indispensable for minimizing the climate change induced adverse impact of extreme weather anomalies, increasing agro-ecosystems resilience and minimizing negative socioeconomic consequences for the regional inhabitant of Eastern India. The balancing between economic developmental activities and socio-economic empowerment towards sustainable growth and economic prosperity against the periodic weather aberrations over eastern India in near future. Nevertheless, the complexity in climate change induced anomalies of regional extreme temperature and precipitation events necessitates more elaborative mechanism-based studies on realistic projections of regional weather phenomenon across the Eastern Indian region.

Acknowledgement: We acknowledge daily weather dataset available from National Data Center, IMD-Pune, India with financial support from NICRA project (code: OXX01713).

\section{Authors' contributions:}

- Data analysis and map generation: Saurav Saha, Debasish Chakraborty, Bappa Das, S. Sadhu, Aakash Chhabra 
- Manuscript preparation: Saurav Saha, Debasish Chakraborty, Debashis Chakraborty, Bappa Das

- Manuscript checking: Samarendra Hazarika, I Shakuntala, Lungmuana, VK Mishra

- Data collection: Saurav Saha, J. Mukherjee, Samarendra Hazarika

Availability of data and material: The dataset is under copyright of India Meteorological Department, Pune. The datset will be available on reasonable request.

Code availability: The $\mathrm{R}$ code will be available on reasonable request.

\section{Declarations (ethics):}

Conflicts of interest/Competing interests: The authors declare no competing interests.

Ethics approval: Not applicable; the study did not include human or animal subject data.

Consent to participate: Not applicable; the study did not include human or animal subject data.

Consent for publication: Not applicable; the study did not include human or animal subject data.

\section{References:}

Abul Basher Md, Stiller-Reeve MA, Saiful Islam AKM, Bremer S (2017) Assessing climatic trends of extreme rainfall indices over northeast Bangladesh. Theor Appl Climatol. https://doi.org/10.1007/s00704-017-2285-4

Akhoury G, Avishek K (2020). Global atmospheric changes versus the Indian rainfall variation. Arab. J. Geosci. 13:553.

Chakraborty D, Sehgal VK, Dhakar R, Varghese E, Das DK, Ray M (2018). Changes in daily maximum temperature extremes across India over 1951-2014 and their relation with cereal crop productivity. Stoch Environ Res Risk Assess Stoch Env Res Risk A 32(11): 3067-3081.

Choi G, Collins D, Ren G, Trewin B, Baldi M, Fukuda Y, Afzaal M, Pianmana T, Gomboluudev P, Huong PTT, Lias N, Kwon W-T, Boo K-O, Cha Y-M, Zhou Y (2009) Changes in 
means and extreme events of temperature and precipitation in the Asia-Pacific Network region, 1955-2007. Int J Climatol 29:1906-1925.

Choudhury, BU, Das A, Ngachan, SV, Slong A, Bordoloi LJ, Chowdhury P (2012) Trend analysis of long term weather variables in mid altitude Meghalaya, North-East India. J Agric Phys 12:12-22.

Dahutia P, Pathak B, Bhuyan PK (2018) Aerosols characteristics, trends and their climatic implications over Northeast India and adjoining South Asia. Int J Climatol 38:12341256.

Dang S, Yu K, Tao S, Han T, Zhang H, Jiang W (2020) El Niño/Southern Oscillation during the 4.2 ka event recorded by growth rates of corals from the North South China Sea. Acta Oceanol Sin 39(1):110-117.

Goddard L, Gershunov A (2021) Impact of El Niño on Weather and Climate Extremes. In El Niño Southern Oscillation in a Changing Climate, Geophysical Monograph 253, McPhaden MJ, Santoso A, Cai W, (Eds). First Edition, pp. 361-375.

Guhathakurta P, Sreejith OP, Menon PA (2011) Impact of climate change on extreme rainfall events and flood risk in India. J Earth Syst Sci 120(3):359-373

Hurst H (1951) Long term storage capacity of reservoirs. T Am Soc Civ Eng 6:770-799.

Ihara C, Kushnir Y, Cane MA, Victor H, Peña De La (2006) Indian summer monsoon rainfall and its link with ENSO and Indian Ocean climate indices. Int J Climatol 27(2):179-187

IPCC (2013) Climate Change 2013: The Physical Science Basis. Contribution of Working Group I to the Fifth Assessment Report of the Intergovernmental Panel on Climate Change [Stocker TF, Qin D, Plattner G-K, Tignor M, Allen SK, Boschung J, Nauels A, Xia Y, Bex V, Midgley PM (eds)]. Cambridge University Press, Cambridge, United Kingdom and New York, NY, USA, 1535 pp.

Jaswal AK (2010) Changes in total cloud cover over India based upon 1961-2007 surface observations. Mausam 61(4):455-468. 
Jhajharia D, Singh VP (2011) Trends in temperature, diurnal temperature range and sunshine duration in northeast India. Int J Climatol 31:1353-1367.

Johansen S, Juselius K (1990) Maximum likelihood estimation and inference on cointegrationwith applications to the demand for money. Oxf. Bull. Econ. Stat. 52(2):169-210.

Joshi MK, Rai A (2014) Combined interplay of the Atlantic multidecadal oscillation and the interdecadal Pacific oscillation on rainfall and its extremes over Indian subcontinent. Clim Dyn. https://doi.org/10.1007/s00382-014-2333-z

Karki R, Hasson S, Gerlitz L, Talchabhade R, Schickhoff U, Scholten T, Böhner J (2019) Rising mean and extreme near-surface air temperature across Nepal. Int $\mathbf{J}$ Climatol. https://doi.org/10.1002/joc.6344

Klein Tank AMG, Peterson TC, Quadir DA, Dorji S, Zou X, Tang H, Santhosh K, Joshi UR, Jaswak AK, Kolli RK, et al. (2006) Changes in daily temperature and precipitation extremes in central and south Asia. J Geophys Res 111:D16105.

Kumar P (2021) Impact of Climate Change and Surface Energy (Im) Balance on North-East India Monsoonal Rainfall. J Clim Change 7(2): 35-47

Mandal DK, Mandal C, Singh SK (2016) India agro-ecological regions (Revised), ICARNBSS\&LUP Publ. No. 170, ICAR-NBSSLUP, Nagpur, India, pp.1-73.

Misra V; Groenen D, Bhardwaj A, Mishra A, Bharadwaj A (2016) The warm pool variability of the tropical northeast Pacific. Int J Climatol 36:4625-4637

Nikumbh AC, Chakraborty A, Bhat G (2019). Recent spatial aggregation tendency of rainfall extremes over India. Scientific Reports 9(1):1-7. https://doi.org/10.1038/s41598-01946719-2

Panda DK, Kumar A (2014) The changing characteristics of monsoon rainfall in India during 1971-2005 and links with large scale circulation. Int J Climatol 34:3881-3899. https://doi.org/10.1002/joc.3948

Prasad KD, Singh SV (1996) Forecasting the spatial variability of the Indian monsoon rainfall using canonical correlation. Int J Climatol 16:1379-1390 
Prokop P, Walanus A (2014) Variation in the orographic extreme rain events over the Meghalaya Hills in northeast India in the two halves of the twentieth century. Theor Appl Climatol. https://doi.org/10.1007/s00704-014-1224-X

Rapp D (2014) Assessing climate change. In: Temperatures, Solar Radiation and Heat Balance. Springer.

Revadekar JV, Kothawale DR, Patwardhan SK, Pant GB, Rupa Kumar K (2013) About the observed and future changes in temperature extremes over India. Nat Hazards 60:11331155.

Roy I, Tedeschi RG, Collins M (2019) ENSO teleconnections to the Indian summer monsoon under changing climate. Int J Climatol 39:3031-3042

Saha S, Chakraborty D, Paul RK, Samanta S, Singh SB (2018) Disparity in rainfall trend and patterns among different regions: analysis of 158 years' time series of rainfall dataset across India. Theor Appl Climatol 134(1-2):381-395.

Sein KK, Chidthaisong A, Oo KW (2018) Observed Trends and Changes in Temperature and Precipitation Extreme Indices over Myanmar. Atmosphere 9:477.

Sen Roy S, Balling RC (2004) Trends in extreme daily precipitation indices in India. Int J Climatol 24: 457-466.

Sharma PJ, Loliyana VD, Resmi SR, Timbadiya PV, Patel PL (2017) Spatio-temporal trends in extreme rainfall and temperature indices over Upper Tapi Basin, India. Theor Appl Climatol 1-26.

Song M, Ma Y, Zhang Y, Li M, Ma W, Sun F (2011) Climate change features along the Brahmaputra Valley in the past 26 years and possible causes. Clim Change 106:649660. DOI 10.1007/s10584-010-9950-2

Trenberth KE (2011) Changes in precipitation with climate change. Clim Res 47: 123-138.

Wang XL, Feng Y (2013) RHtestsV4 user manual. Environment Canada Science and Technology Branch, Climate Research Division, Atmospheric Science and Technology, Directorate Science and Technology Branch, Environment Canada, Toronto, Ontario, Canada 
620 Weller E, Min Seung-Ki, Wenju C, Zwiers, Francis W, Yeon-Hee K, Donghyun L, (2016) Human621 caused Indo-Pacific warm pool expansion. Science Advances. 2(7):e1501719.

622 Zahan Y, Mahanta R, Rajesh PV, Goswami BN (2021a) Impact of climate change on North-East 623 India (NEI) summer monsoon rainfall. Clim Change 164(2). 624 https://doi.org/10.1007/s10584-021-02994-5

625 Zahan, Y, Rajesh BPV, Choudhury A, Goswami BN (2021b) Why Indian summer monsoon 626 circulation indices? Fidelity in representing rainfall variability and teleconnections. Q J $627 \quad$ R Meteorol Soc 147 (735): 1300-1316.

628 Zhang, X, Feng, Y, Chan R (2018). Introduction to RClimDex v1. 9. Climate Research Division 629 Environment Canada Downs view, Ontario Canada. 


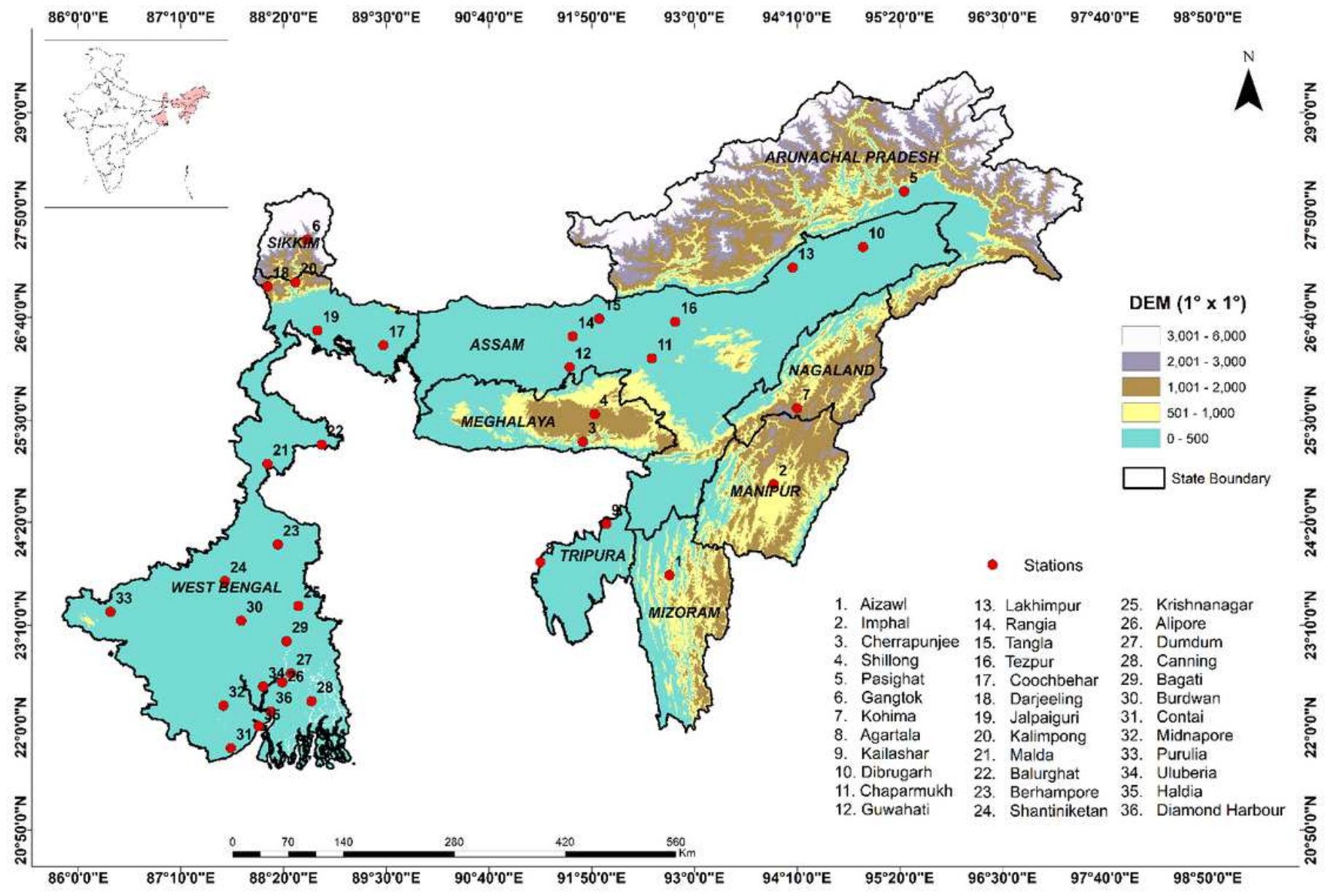

\section{Figure 1}

The study region and location of surface weather stations across eastern India. 

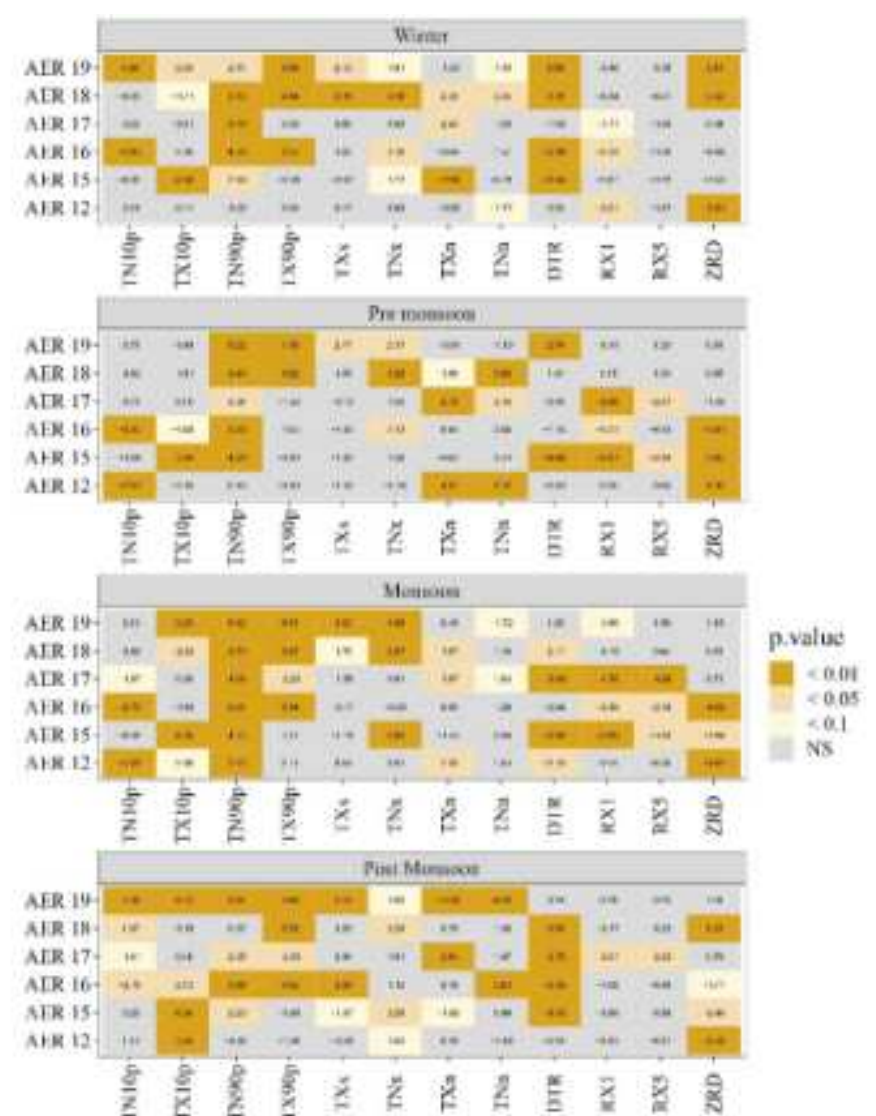

Aamid

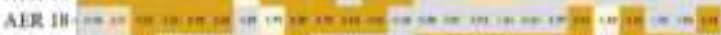

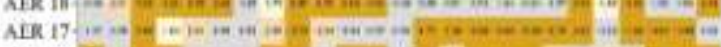

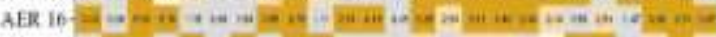
ATR is 10.0 in in

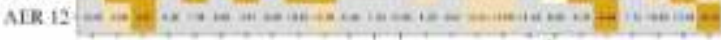

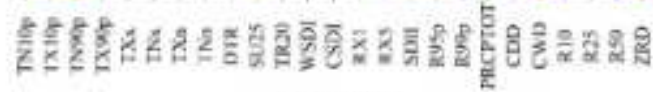
Parimeters

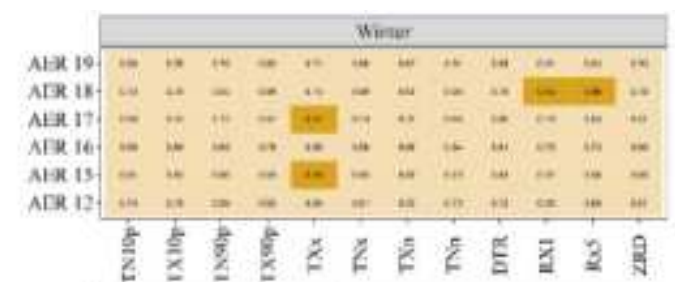

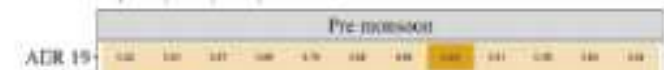

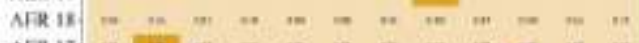

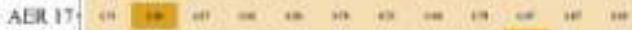

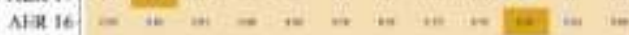

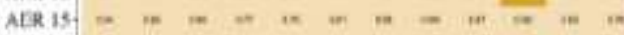

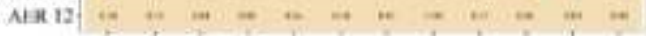

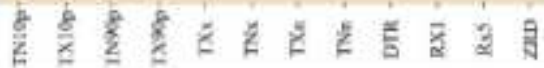

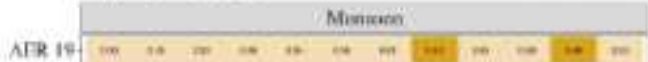

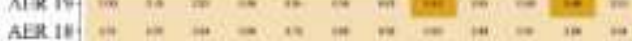

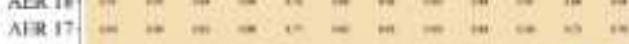

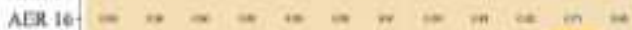

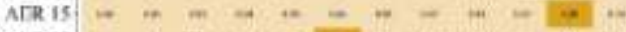

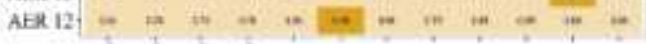

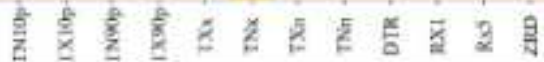

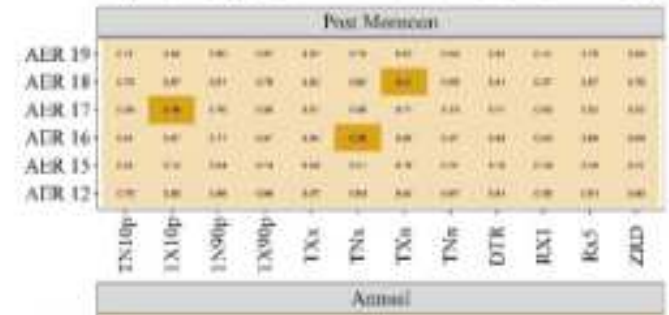

AER 19.

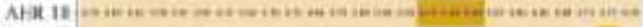

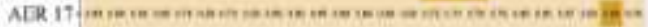

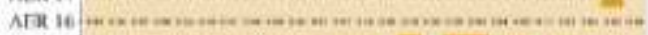

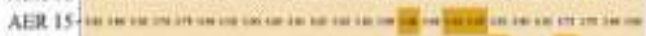
wax

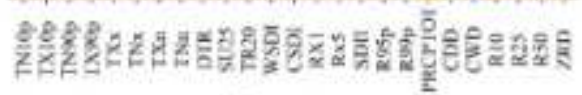

Parameters
Hexponent

III Aat penisiense Menisente

\section{Figure 2}

(a) Regional trend pattern and (b) trend persistence in seasonal and annual extremes across six agroecoregions of eastern India 
(a

El Nino

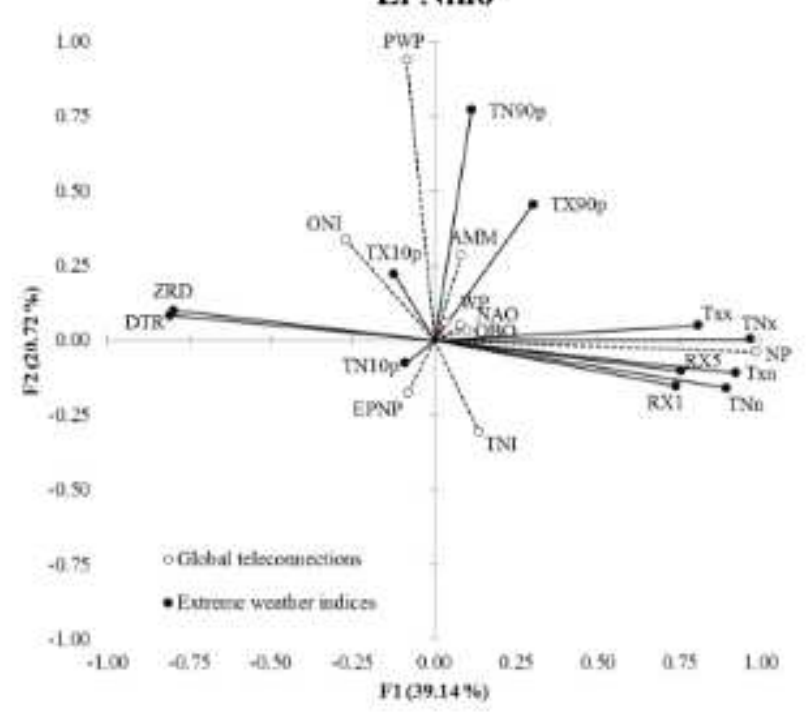

(c

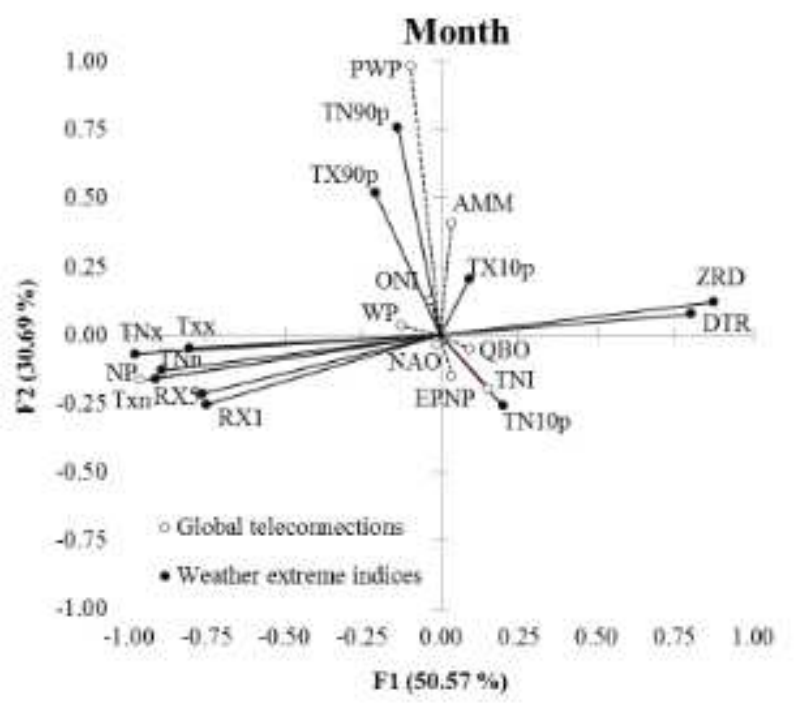

(b)

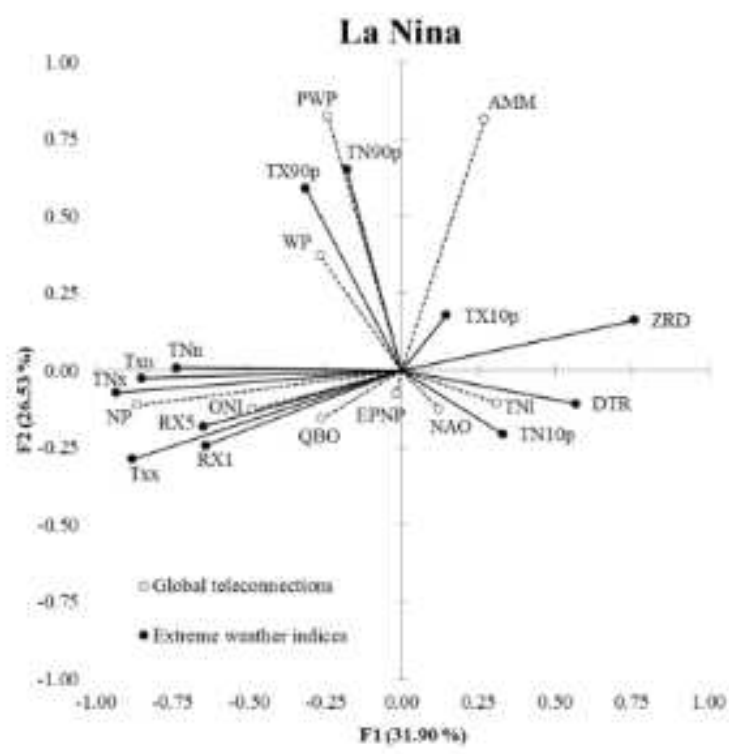

(d)

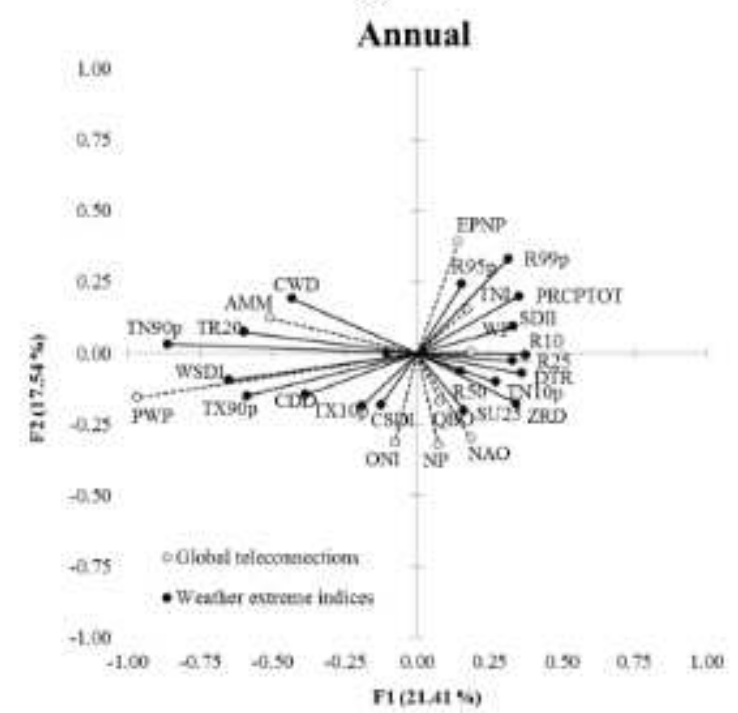

Figure 3

Canonical correlation plot between global teleconnection and weather extreme events over eastern India during (a) El nino years (b) La Nina years (c) monthly and (d) annual time scale.

\section{Supplementary Files}

This is a list of supplementary files associated with this preprint. Click to download.

- Supplementarylnformation.docx 